\title{
Prevalence of Metabolic Syndrome and Its Components among Overweight and Obese Secondary School Adolescent in SFAX, Tunisia
}

\author{
Sofien Regaieg ${ }^{1}$, Nadia Charfi ${ }^{1}$, Sourour Kamoun ${ }^{2}$, Mouna Eulleuch $^{3, *}$, Rim Marrakchi $^{4}$, Kamel jamoussi ${ }^{4}$, \\ Jamel Damak $^{2}$, Mohamed Abid ${ }^{1}$ \\ ${ }^{1}$ Unit of Obesity and Metabolic Syndrome (UR04SP31), Department of Endocrinology, Hedi Chaker Hospital, University of Sfax, Tunisia \\ ${ }^{2}$ Department of Community Medicine and Epidemiology, Hedi Chaker Hospital, Sfax, Tunisia \\ ${ }^{3}$ Department of internal medicine, Sidi Bouzid Hospital, Tunisia \\ ${ }^{4}$ Biochemistry Laboratory, Hedi Chaker Hospital, Sfax, Tunisia \\ *Corresponding author: elleuch_mouna@yahoo.fr
}

Received March 11, 2015; Revised March 23, 2015; Accepted March 26, 2015

\begin{abstract}
Objective: The metabolic syndrome (MetS) has become one of the major public-health challenges worldwide. Early identification of metabolic complications consist an essential target for youth public health. We aimed to evaluate the prevalence of MetS and its components among overweight and obese adolescents. Methods: This cross-sectional study concerned 51 overweight and obese adolescents. Anthropometric assessments, blood pressure measurement and biochemical assessment were done. MetS was defined according to the International Diabetes Federation (IDF) criteria. All data were collected during one academic school year in 2012 and 2013. Results: The prevalence of the MetS was 21.6\%. There was no gender difference in prevalence of MetS $(\mathrm{P}=0.09)$. Obese subjects had the highest proportion of MetS than overweight ( $25 \%$ vs. $15.8 \%$; $\mathrm{p}=0.04)$. $35.3 \%$ of subjects had at least two abnormalities of MetS. Abdominal obesity was the most common individual component of the MetS (91.3\%) followed by low HDL cholesterol (58.8\%). Body mass index (BMI), Waist circumference (WC), Waist to hip ratio (WRH) and Neck circumference (NC) had partial positive correlation with Blood pressure (BP), and Triglyceride. Similarly, (BP), Triglyceride and HDL cholesterol were significantly higher in subjects with metabolic syndrome than that of subjects without metabolic syndrome $(p<0.05)$. Conclusion: MetS is prevalent in our young population in Sfax City. The results of this study will help in planning to control these problems in the future. So we suggest screening programs for secondary school adolescent to control obesity and MetS in Tunisia.
\end{abstract}

Keywords: metabolic syndrome, obesity, prevalence, adolescent

Cite This Article: Sofien Regaieg, Nadia Charfi, Sourour Kamoun, Mouna Eulleuch, Rim Marrakchi, Kamel jamoussi, Jamel Damak, and Mohamed Abid, "Prevalence of Metabolic Syndrome and Its Components among Overweight and Obese Secondary School Adolescent in SFAX, Tunisia." International Journal of Clinical Nutrition, vol. 3, no. 1 (2015): 1-6. doi: 10.12691/ijcn-3-1-1.

\section{Background}

Metabolic syndrome (MetS) is a constellation of metabolic abnormalities that includes abdominal obesity, glucose intolerance, hypertension, elevated triglycerides and low High Density Lipoprotein cholesterol (HDL-c). This clustering is associated with increased risk of developing diabetes and cardiovascular disease (CVD) [1]. The development of MetS during adolescence may differ from that in adulthood. [2]. Thus, prevalence of this entity is dependent on the definition that is used to determine inclusion as well as the composition (e.g., sex, age, and ethnicity) of the population being studied [2,3,4]. Recent studies have shown that the MetS develops during childhood; as a consequence of increasing rates of obesity [2,3,5]. In fact, the dramatic rise in childhood obesity in developing countries is considered a major driving force behind the increasing prevalence of MetS [3]. Tunisia is undergoing a socio-economic and nutrition transition especially in large cities, where lifestyles are becoming more sedentary with lower levels of physical activity, and diets with higher fat content [6,7]. This has brought an increased risk of CVD and other chronic diseases [7]. The emergent epidemic of obesity in children and adolescents makes MetS and its sequel an important condition to study in Tunisia $[7,8]$. Nevertheless, previous studies have shown that features of the MetS develop early in life and can be predictive of atherosclerotic processes in adulthood $[9,10]$. However, children and adolescents are not routinely screened for MetS. The obesity and their relation to of MetS in adolescent have been inadequately studied in Tunisia. [7,8,11,12].

The aim of the present study is to estimate the prevalence of the MetS and its components by gender among overweight and obese adolescents aged 15-18 
years in Sfax City according to the International Diabetes Federation (IDF) guidelines definition [13].

\section{Material and Methods}

\subsection{Study Population}

The present study was conducted with the agreement of the Ministry of Education and the Ethics Committee of Hedi Chker Hospital, Sfax, Tunisia. All participating pupils and their parents provided written consent; participants received no incentives, and could withdraw from the study if they wished. All data were collected during one academic school year in 2012 and 2013.

Our population was recruited from a school-based cross-sectional study conducted by the Unit of Obesity and Metabolic Syndrome, Department of Endocrinology, Hedi Chaker Hospital Sfax and designed to examine the prevalence of overweight and obesity among pupils of the secondary school Majida Boulila, Sfax. The school where the study was implemented was selected on the basis that it is the largest school in Sfax City, with 2410 pupils. Briefly, 1695 pupils participated in this study. The prevalence of overweight and obesity were 19, $2 \%$ and 4 , $2 \%$ respectively.

A total of 100 overweight and obese adolescents were randomly selected according to the weight status, age and sex to participate in $r$ the study. Complete data were obtained from 51 pupils (28 girls and 23boys) ; 32 obese and 19 overweight aged 15 to 18 years. Subjects were eligible if: (a) were between 15 and 18 years old, (b) a Body Mass Index (BMI) above or equal to the value that predicted overweight or obesity by applying the age and sex specific International Obesity Task Force (IOTF) BMI cut off points[14], (c) good health and no recent (previous 2 years) systemic illness; (d) no known history of chronic disease; (e) no orthopedic disease or injury limiting physical activity; (f) no medications, which might influence cardiovascular function, lipid, or glucose metabolism. The exclusion criteria include: (a) parents did not allow their child to participate in this study, or did not sign the informed consent, (b) subject who was severely sick during the time of study or (c) did not present on the day of study.

\subsection{Data Collection}

All measurements were conducted in school clinic and performed by school nurse. Anthropometric standardization exercises were conducted to ensure uniform techniques. All subjects went through physical examination including, anthropometric assessments blood pressure and biochemical assessment.

Weight was measured without shoes and heavy clothes, using a Tanita electronic scale (Tanita BF 571, Tanita Corporation, Japan) and was recorded to the nearest $100 \mathrm{~g}$. Standing height was measured with a suspended Microtoise tape to the nearest $0.1 \mathrm{~cm}$. Body mass index (BMI) was calculated as weight in kilograms divided by the square of height in meters $(\mathrm{kg} / \mathrm{m} 2)$. The subjects were classified as overweight/obese by applying the age and sex (IOTF) BMI cut off points.

Waist circumference (WC) was measured in $\mathrm{cm}$ with a non-elastic tape applied at a point midway between the lower border of the rib cage and the iliac crest at the end of normal expiration. Hip circumference (HC) was measured in centimeters at the greater trochanter of the femur with the legs close together using a non-stretchable measuring tape. Waist to Hip ratio (WHC) was calculated by dividing WC with $\mathrm{HC}$.

Neck circumference was measured in the midway of the neck, between mid-cervical spine and mid anterior neck, to within $1 \mathrm{~mm}$, using non-stretchable plastic tape with the subjects standing upright, head erect and eyes facing forward. In men with a laryngeal prominence (Adam's apple), it was measured just below the prominence.

Determination of pubertal development was assessed by a self-administered confidential questionnaire using diagrams illustrating the five stages of pubertal development [15]. Pubertal stage was grouped into pre-pubescent, pubescent and post-pubescent based on the WHO definition [16].

The blood pressure (BP) was measured using participants' right arm after they had been resting in a seated position for 15 minutes. Systolic blood pressures (SBP) and Diastolic blood pressures (DBP) were measured manually in mmHg with Nova sphygmomanometer. The subject was in a seated, relaxed position and recordings were made 2 times at 10 minute intervals. The measurements were taken in millimeters of mercury and the mean value of the two recordings (not varying by more than $5 \mathrm{~mm} \mathrm{Hg}$ ) was calculated. The means of two systolic and two diastolic blood pressures were recorded.

\subsection{Laboratory Measurements}

Blood samples were taken by venipuncture after a fasting of 12 hours. The blood was collected in heparinate of lithium tubes. All laboratory analyses were carried out at the biochemistry laboratory of University Hospital Hedi Cheker Sfax.

Plasma was obtained by centrifugation for 10 minutes at $2000 \mathrm{x}$ g. All samples were tested within 2 hours after prelevement for Total cholesterol, triglycerides, high density lipoprotein cholesterol (HDL-C), and glucose on a multiparametric analyzer Unicel TM DXC 600® Beckman Coulter.

\subsection{Definition of Metabolic Syndrome}

Subjects were classified as having metabolic syndrome according to the International Diabetes Federation (IDF) guidelines [13]. Metabolic syndrome was defined as adolescents with waist circumference greater or equal to $(\geq)$ 90th percentile and two or more of the following components: Systolic/diastolic blood pressure $\geq 130 / 85$ $\mathrm{mmHg}$,

- Fasting plasma glucose $\geq 5.6 \mathrm{mmol} / \mathrm{L}$,

- Serum triglycerides $\geq 1.7 \mathrm{mmol} / \mathrm{L}$,

- Serum HDL-C $<1.03$ mmol/L.

Concerning, the measure of waist circumference, we used the cut-off points recommended by Rolland-Cachera et al [17]. For adolescent older than 16 years, we used the IDF adult criteria [13].

\subsection{Statistical Analysis}

Statistical analysis was conducted using SPSS version 20 (SPSS Inc. Chicago, IL, USA). Quantitative variables were expressed as mean-standard deviation. Qualitative 
variables were expressed as number and (percentage). Comparisons were performed using Pearson's chi-squared for qualitative and Student's t-test for quantitative variables. P-values below 0.05 were considered to be statistically significant.

\section{Results}

A total of 51 overweight and obese adolescents, living in an urban area of Sfax (Southeast of Tunisia) participated in this study. The proportion of males was
45.1\%. According to (IOTF) BMI cut off points, $37.7 \%$ of subjects were overweight and $62.3 \%$ obese.

The mean age of the sampled subjects was $16.8 \pm 0.69$ years. There were 18 subjects in the age group 15 to 16 years and 33 in 16-18 years. All the participants had attained puberty.

Mean and standard deviation of anthropometric variables and biochemical factors are presented in Table 1. The mean weight, height, WC, WHR and NC of the male students were significantly higher than those of the females $(\mathrm{p}<0.05)$.

Table 1. Clinical characteristics in overweight and obese adolescents, aged 15-18 years, living in Sfax (Tunisia) and stratified by gender

\begin{tabular}{|c|c|c|c|c|}
\hline Characteristics & $\begin{array}{c}\text { Total } \\
\text { Mean } \pm \text { SD } \\
\end{array}$ & $\begin{array}{c}\text { Boys } \\
\text { Mean } \pm \text { SD }\end{array}$ & $\begin{array}{c}\text { Girls } \\
\text { Mean } \pm \text { SD }\end{array}$ & $P$ valuea* \\
\hline Age (years) & $16.80 \pm 0.69$ & $16.74 \pm 0.75$ & $16.86 \pm 0.65$ & 0.55 \\
\hline weight $(\mathrm{kg})$ & $90.14 \pm 16.4$ & $99.26 \pm 16.81$ & $82.64 \pm 11.83$ & 0.001 \\
\hline Height(cm) & $169.2 \pm 8.4$ & $175.3 \pm 6.83$ & $164.21 \pm 5.93$ & 0.001 \\
\hline Body mass index $(\mathrm{kg} / \mathrm{m} 2)$ & $31.27 \pm 367$ & $32.15 \pm 3.88$ & $30.54 \pm 3.17$ & 0.11 \\
\hline Waist circumference $(\mathrm{cm})$ & $95.16 \pm 12.1$ & $102.09 \pm 13.07$ & $89.5 \pm 76$ & 0.001 \\
\hline Hip circumference (cm) & $106.37 \pm 10.53$ & $107.3 \pm 12,12$ & $106.14 \pm 9.21$ & 0.7 \\
\hline Waist to hip ratio & $0.89 \pm 0.09$ & $0.95 \pm 0.075$ & $0.84 \pm 0.06$ & 0.001 \\
\hline Neck circumference $(\mathrm{cm})$ & $35.12 \pm 3.8$ & $38.26 \pm 2.49$ & $32.54 \pm 2.6$ & 0.001 \\
\hline Systolic blood pressure (mmHg) & $123.98 \pm 9.3$ & $126.48 \pm 9.88$ & $121.93 \pm 8.48$ & 0.083 \\
\hline Diastolic blood pressure (mmHg) & $68.9 \pm 7.4$ & $69.35 \pm 7.39$ & $68.54 \pm 7.6$ & 0.67 \\
\hline Fasting plasma glucose $(\mathrm{mmol} / \mathrm{L})$ & $4.5 \pm 0.37$ & $4.65 \pm 0.31$ & $4.47 \pm 0.41$ & 0.075 \\
\hline HDL- c $(\mathrm{mmol} / \mathrm{L})$ & $1.09 \pm 0.24$ & $1.05 \pm 0.21$ & $1.13 \pm 0.26$ & 0.22 \\
\hline Triglyceride $(\mathrm{mmol} / \mathrm{L})$ & $0.91 \pm 0.51$ & $1.05 \pm 0.49$ & $0.8 \pm 0.5$ & 0.05 \\
\hline Cholesterol (mmol/L) & $3.97 \pm 0.7$ & $4.1 \pm 0.74$ & $3.7 \pm 0.66$ & 0.25 \\
\hline
\end{tabular}

* Comparison between genders, HDL-c: high-density lipoprotein cholesterol, SD, standard deviation.

Table 2 shows the prevalence of the Mets and its males and 89. 3\% in females. No adolescent in our study components, according to FID criteria stratified by gender and weight status. The overall prevalence of the MetS was $21.6 \%$. There was no gender difference in prevalence of MetS $(\mathrm{P}=0.09)$. Twenty five percent of obese and $15.8 \%$ of overweight group met the criteria of MetS, the difference between the two groups was significant $(\mathrm{P}=0.04)$. Among all the components of metabolic syndrome, high WC was most prevalent with $91.3 \%$ in had hyperglycemia. Moreover, $58.8 \%, 27.4 \%$ and $9.8 \%$ of them had decreased HDL cholesterol, elevated blood pressure and hypertriglycerideamia respectively. Prevalence of subjects with 1 or more components of MetS is presented in Figure 1. 36.9\% of the overweight and $68.7 \%$ of the obese adolescents had at least two abnormalities of the MetS.

Table 2. Prevalences of the metabolic syndrome and its components, according to International Diabetes Federation criteria, among 51 overweight and obese adolescent aged 15-18 years, living in Sfax (Tunisia) and stratified by gender and BMI status

\begin{tabular}{|c|c|c|c|c|c|}
\hline \multirow{2}{*}{ Parameters } & \multicolumn{5}{|c|}{ Prevalence \% } \\
\hline & Girls & Boys & Overweight & Obese & All subjects \\
\hline Large waist circumference & 89.3 & 91.3 & 73.7 & 100 & 90.1 \\
\hline Elevated blood pressure & 21.4 & 34.8 & 15.8 & 34.4 & 27.4 \\
\hline Low HDL cholesterol & 64.4 & 52.2 & 52.3 & 62.5 & 58.8 \\
\hline High triglyceride level & 10.7 & 8.7 & 10.5 & 9.4 & 9.8 \\
\hline Hyperglycaemia & 0 & 0 & 0 & 0 & 0 \\
\hline Metabolic syndrome present & 21.5 & 21.7 & 15.8 & 25 & 21.6 \\
\hline
\end{tabular}

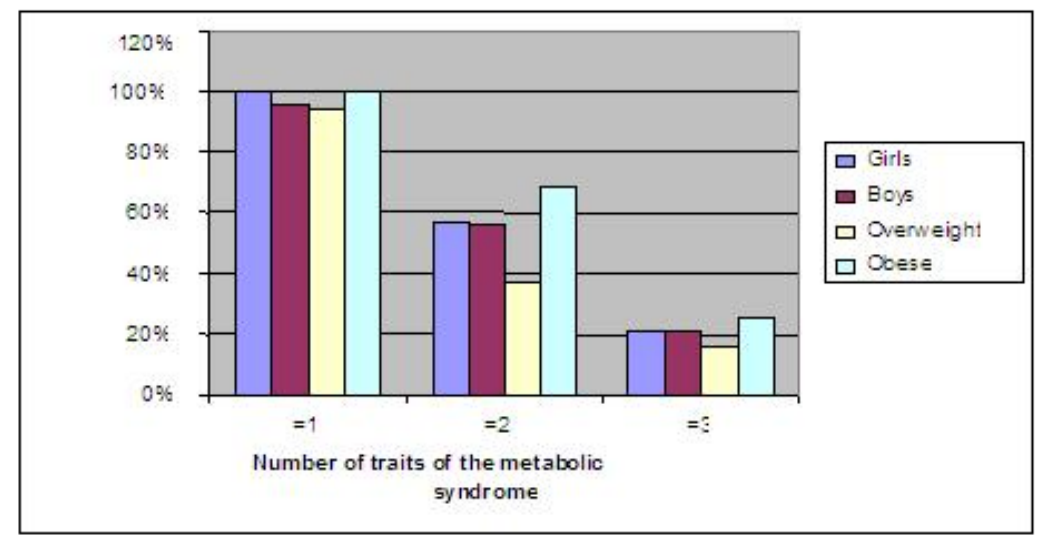

Figure 1. Prevalence of components of the metabolic syndrome, according to International Diabetes Federation criteria, among overweight and obese adolescent aged 15-18 years, living in Sfax (Tunisia) and stratified by gender and BMI status 
While comparing anthropometric and biochemical parameters between two groups (Table 3), we notice that, BMI, WHR, BP, Triglyceride and HDL cholesterol were significantly higher in subjects with metabolic syndrome than that of subjects without metabolic syndrome $(p<$ 0.05).

Table 3. Comparisons of anthropometric and metabolic parameters between subjects with and without the metabolic syndrome

\begin{tabular}{|c|c|c|c|}
\hline Characteristics & $\begin{array}{c}\text { Metabolic Syndrome } \\
\text { Mean } \pm \text { SD }\end{array}$ & $\begin{array}{c}\text { Non-metabolic Syndrome } \\
\text { Mean } \pm \text { SD }\end{array}$ & $p$-value \\
\hline Age (years) & $16.82 \pm 0.75$ & $16.8 \pm 0.69$ & 0.93 \\
\hline Sex (Girls/Boys) & $6 / 5$ & $22 / 18$ & 0.7 \\
\hline Body weight (kg) & $97.27 \pm 20.4$ & $88.18 \pm 14.9$ & 0.10 \\
\hline Height $(\mathrm{cm})$ & $170.36 \pm 9.51$ & 168. $9 \pm 8.17$ & 0.6 \\
\hline Body mass index (kg/m2) & $33.19 \pm 3.89$ & $30.73 \pm 3.32$ & 0.04 \\
\hline Waist circumference (cm) & $101.0 \pm 13.9$ & $93 \pm 5.8$ & 0.07 \\
\hline Hip circumference $(\mathrm{cm})$ & $108.00 \pm 13.2$ & $106.30 \pm 9.83$ & 0.07 \\
\hline Waist to hip ratio & $0.93 \pm 0.09$ & $0.88 \pm 0.08$ & 0.04 \\
\hline Neck circumference $(\mathrm{cm})$ & $36.91 \pm 4.32$ & $34.63 \pm 3.53$ & 0.06 \\
\hline Systolic blood pressure (mm Hg) & $135.0 \pm 5.97$ & $120.95 \pm 7.7$ & 0.001 \\
\hline Diastolic blood pressure (mm Hg) & $72.45 \pm 7.1$ & $67.93 \pm 7.25$ & 0.07 \\
\hline Blood glucose (mmol/L) & $4.71 \pm 0.54$ & $4.51 \pm 0.31$ & 0.12 \\
\hline HDL-c $(\mathrm{mmol} / \mathrm{L})$ & $0.88 \pm 0.18$ & $1.15 \pm 0.22$ & 0.00 \\
\hline Triglycéride (mmol/l) & $1 . .32 \pm 0.59$ & $0.80 \pm 0.42$ & 0.02 \\
\hline Cholesterol (mmol/L) & $4.20 \pm 0.71$ & $3.91 \pm 0.69$ & 0.24 \\
\hline
\end{tabular}

Japanese males (1.3\% and $15.6 \%$, respectively) [28].

\section{Discussion}

The metabolic syndrome among overweight and obese adolescents continues to increase in both developed and developing countries and it has already become a major threat to global public health [18]. It is interesting to know the actual situation in Sfax, the second biggest city in Tunisia. To our knowledge, this is the first study addressing the prevalence of MetS and its components in this City. The number of patients is not the ideal to try to show the prevalence in the entire city, but it would be an initial point for future studies. In this study, approximately $21.6 \%$ of adolescents met the criteria for the MetS. Our findings indicate that the prevalence of MetS among overweight and obese adolescents in Sfax City was comparable to similar studies in other countries $[18,19,20]$, and was slightly lower, compared to the other surveys in Tunisia. In fact, Jamoussi et al [8] found that the prevalence of MetS among overweight and obese children and adolescents (6-18year) in Great Tunis was 34.4\%.

Puberty is a crucial time for the development of the MetS, and yet it is a difficult period to identify this entity [22]. Thus, the prevalence of the MetS in adolescents may vary by sex, as it does in adults [21], but data are conflicting. In the present study, there is no sex difference in the prevalence of MetS (boys $21.7 \%$ and girls 21.5\%), which is consistent with the findings in study by Jamoussi et al in great Tunis (40.8\% in males and $32.1 \%$ in females; $\mathrm{p}=0.27$ ) as in other countries $[9,23,24,25]$. However, in a national multiethnic study by Cook et al [26], the MetS was significantly more prevalent in males $(6.1 \%)$ than in females $(2,1 \%)$.

Previous studies reported that MetS may be on the rise in adolescents with increasing rates of obesity $[2,8,23]$. According to the IDF criteria, prevalence of MetS in the present study was $15.8 \%$ in overweight group and $25 \%$ in obese individuals. These observations were higher than reported prevalence for overweight and obese children and adolescents in South Korean adolescents (1.5\% and 14.7\%, respectively) [27], and for mildly obese and obese
However, the prevalence of MetS among overweight and obese adolescents in Sfax is lower than reported prevalence of overweight and obese children and adolescents, in Great Tunis (25\% and 35\%, respectively) [8], India (11.5\%.and 36.6\%, respectively) [29], Chinese adolescents (23.4\% and 35.2\%, respectively) [30], and moderate to severely obese USA adolescents (38.7\% and $49.7 \%$ respectively) [2]. Our findings were also consistent with other studies $[8,20,23,31]$, which showed that, more than half overweight and obese adolescents had at least two abnormalities of metabolic syndrome, indicating that these subjects may develop MetS later in life.

Friedemann et al noted that obesity was associated with worse risk parameters for cardiovascular disease in school aged children [31]. The anthropometrics measurements are a useful index for estimating the risk factors associated with excess abdominal fat such as type 2 diabetes mellitus, hypertension and hyperlipidemia [32,33]. In the present study, we have found an association between hypertension and anthropometric measurements such as BMI, WC, WHR and NC. Similarly it can be inferred that adolescents with high anthropometrics measurements of (BMI, WC, WHR. and NC) are more likely to have, high triglyceride. These relations between anthropometrics measurements and hypertension and/ or triglyceride level have been established in a number of cross-sectional studies $[5,31,32,33,34,35]$. Our findings showed that subjects with MetS had an increase BMI and WHR measurements compared to others without MetS. It appears, in part, that central adiposity contributes to the high incidence of individual MetS components. Central obesity, considered a key component of the MetS, is a good example of the problem of defining risk levels in children and adolescent $[13,20,32]$. It was noted that, WC is a sensitive marker for abdominal obesity in the pediatric age group [20,32]. However, WC is not widely measured in clinical practice and the school health examination in Tunisia. There are no reference values for waist circumferences exist for children and adolescents in Tunisia.

In accordance with other studies [8,20,26,36] abdominal obesity was also the most common individual 
component of the metabolic syndrome among overweight and obese adolescents in Sfax. This finding will be alarming for this group because abdominal adiposity is considered high-risk fat, and it can predict the risk of Type 2 diabetes and CVD in future [2,31]. The precise causes of the high prevalence of abdominal adiposity have not been entirely elucidated; these may be probably due to greater intake of dietary fat and the lack of sufficient physical activities. In Tunisia, food consumption patterns have changed markedly during the past 4 decades. There has been a shift from traditional eating habits, with a diet rich in cereals, fruits and vegetables to foods with undesirable composition of excessive carbohydrates and sugars [6,7,22].

Similar to the previous surveys $[19,20,23,25,26,29,30]$ the prevalence of low HDL-cholesterol in this study was frequent. Our findings showed that, adolescents with MetS were reported to have low HDL cholesterol and high triglycerides than subjects without MetS, which is not contradictory to the other studies owing to the relationship between HDL-C and TG, as low HDL-C is brought about by high TG levels [31,35].

Hypertension is recognized as an important component of the metabolic syndrome in adults, but its role in children and adolescents is not clear [22]. The prevalence of hypertension was $27.4 \%$ in this study and was consistent with recent studies $[8,19,23,28,29,30,36]$ that showed that the prevalence of hypertension in overweight and obese adolescent ranged from 15\% - $51 \%$ depending on gender, age, the severity of obesity and the criteria used to define hypertension. The changes in blood pressure during puberty may be influenced also by the decrease in physical activity and changes in eating habits that are commonly seen during adolescence [21].

No adolescent in our study had hyperglycemia, which is in agreement with other studies [23,26,29,36] that found that hyperglycemia is an infrequent abnormalities. However, this result contrasts with the Korean studies that found glucose intolerance was the dominant feature of the MetS [27].

In several studies, overweight youth had low HDL cholesterol and high triglycerides and insulin, but normal glucose levels than non-overweight subjects, suggesting that glucose intolerance may develop later than other syndrome abnormalities [21,29,37,38]. Thus, it may be important to assess insulin levels as well as glucose, because many with the cluster of metabolic syndrome factors will have normal glucose levels [21].

This heterogeneity of these results suggests that genetic and ethnic factors play an important role in the development of metabolic syndrome and it is important to take into account the role of these factors when assessing the different components [23].

Our study had several limitations. First, the sample size of the study, in fact the number of patients was not the ideal to try to show the prevalence of MetS among overweight and obese adolescent in the entire city. Second, others risk factors that may be associated with MetS were not examined. In fact, we did not take into account some possible confounders such as physical activity, dietary habits, and socioeconomic status in our analysis. Similarly, family medical history including cardiovascular diseases, obesity, diabetes and hypertension was a predisposing factor for the prevalence of the MetS $[37,38,39]$. The MetS begins in childhood or in adolescent (or even earlier, in fetal life) and manifest due to interactions and accumulation of various risk factors, throughout the life course [29,39].

Despite these limitations, our findings contribute to the understanding of the prevalence of the MetS and its components among overweight and obese adolescents aged 15 to 18 years in Sfax City.

The MetS and its many consequences will continue to increase unless we find ways to prevent obesity and the MetS in childhood and adolescence in this region.

\section{Conclusion}

Metabolic syndrome is prevalent in our young obese population in Sfax City. The results of this study may help in designing interventions aimed at modifying unhealthy lifestyle in overweight and obese adolescents which may reduce the later incidence of cardiovascular disease in adults.

The optimal approach towards decreasing the prevalence of this syndrome is lifestyle modification; healthy food habits and maintenance of high level of physical activity. Thus, a multidisciplinary approach involving parents, teachers, and media is needed to address this problem.

\section{Acknowledgement}

No competing financial interests exist.

We would like to thank all adolescents who were part of this study.

\section{References}

[1] Kaplan NM. The deadly quartet. Upper-body obesity, glucose intolerance, hypertriglyceridemia, and hypertension. Arch Intern Med, 1989; 149(7):1514-20.

[2] Weiss R, Dziura J, Burgert TS, Tamborlane WV, Taksali SE, Yeckel CW, Allen K, Lopes M, Savoye M, Morrison J, Sherwin RS, Caprio S. Obesity and the metabolic syndrome in children and adolescents. N Engl J Med, 2004; 350(23): 2362-74.

[3] Beilin L, Huang RC. Childhood obesity, hypertension, the metabolic syndrome and adult cardiovascular disease. Clin Exp Pharmacol Physiol, 2008, 35(4):409-411.

[4] Cornier MA, Dabelea D, Hernandez TL, Lindstrom RC, Steig AJ, Stob NR, Van Pelt RE, Wang H, Eckel RH. The metabolic syndrome. Endocr Rev, 2008 ;29(7):777-822.

[5] Sen Y, Kandemir N, Alikasifoghu A, Gonc N, Ozon A. Prevalence and risk factors of metabolic syndrome in obese children and adolescents: the role of the severity of obesity. Eur J Pediatr, 2008; 167(10): 1183-89.

[6] Ghannem $\mathrm{H}$. The challenge of preventing cardiovascular disease in Tunisia. Prev Chronic Dis, 2006;3(1): A13.

[7] Ben Romdhane H, Haouala H, Belhani A, Drissa H, Kafsi N, Boujnah R, Mechmèche R, Slimane ML, Achour N, Nacef T, Gueddiche M. Epidemiological transition and health impact of cardiovascular disease in Tunisia. Tun Med, 2005; 83(Suppl 5):17.

[8] Jamoussi H, Mahjoub F, Sallemi H, Berriche O. Ounaissa K, Amrouche C, Blouza S. Metabolic syndrome in Tunisian obese children and adolescents. Tun Med, 2012 ; 90 (1 ) : 36-40.

[9] Caceres M, Teran CG, Rodriguez S, Medina M. Prevalence of insulin resistance and its association with metabolic syndrome criteria among Bolivian children and adolescents with obesity. BMC Pediatr, 2008; 8: 31.

[10] Eisenmann JC, Welk GJ, Wickel EE, Blair SN. Stability of variables associated with the metabolic syndrome from adolescence to adulthood: the Aerobics Center Longitudinal Study.Am J Hum Biol, 2004: 16(6):690-96. 
[11] Harzallah F, Alberti H, Ben Khalifa F. The metabolic syndrome in an Arab population: A first look at the new International Diabetes Federation criteria. Diabet Med, 2006; 23(4) :441-4.

[12] Bouguerra R, Ben Salem L, Alberti H, Ben Rayana C, El Atti J, Blouza S, Gaigi S, Achour A, Ben Slama C, Zouari B. Prevalence of metabolic abnormalities in the Tunisian adults: A population based study. Diabetes Metab, 2006; 32(3): 215-21.

[13] Zimmet P, Alberti G, Kaufman F, Tajima N, Silink M, Arslanian S, Wong G, Bennett P, Shaw J, Caprio S: The metabolic syndrome in children and adolescents. Lancet, 2007, 369(9579): 2059-2061.

[14] Cole TJ, Bellizzi MC, Flegal KM, Dietz WH. Establishing a standard definition for child overweight and obesity worldwide: international survey. Br Med J, 2000; 320 (7244): 1240-3.

[15] WHO Expert Committee: Physical status: The use and interpretation of anthropometry: report of a WHO expert committee (WHO Technical Report Series; 854) Geneva. World Health Organ Tech Rep Ser, 1995; 854: 1-452.

[16] Tanner JM: Growth at adolescence; with a general consideration of the effects of hereditary and environmental factors upon growth and maturation from birth to maturity Oxford: Blackwell, 2d, 1962.

[17] Rolland-Cachera MF, Deheeger M, Bellisle F. Waist circumference values in French boys and girls aged 6 to 16 years. Int J Obesity, 2001;25(Suppl. 2):S132.

[18] Roya Kelishadi. Childhood Overweight, Obesity, and the Metabolic Syndrome in Developing Countries. Epidemiol Rev, 2007; 29: 62-76.

[19] Agirbasli M, Cakir S, Ozme S, Ciliv G: Metabolic syndrome in Turkish children and adolescents. Metabolism, 2006, 55(8):10021006

[20] Nasreddine L, Ouaijan K, Mansour M, Adra N, Sinno D, Hwalla $\mathrm{N}$. Metabolic syndrome and insulin resistance in obese prepubertal children in Lebanon: A primary health concern. Ann Nutr Metab, 2010; 57(2) :135-42

[21] Ann Jessup, MSN, RN, APRN, BC; and Joanne S. Harrell, PhD, RN, FAAN, FAHA. The Metabolic Syndrome: Look for It in Children and Adolescents, Too!. Clinical Diabetes, 2005 ;23(1):26-32.

[22] Allal-Elasmi M, Haj Taieb S, Hsairi M, Zayani Y, Omar S, Sanhaji H, Jemaa R, Feki M, Elati J, Mebazaa A, Kaabachi N. The metabolic syndrome: prevalence, main characteristics and association with socio-economic status in adults living in Great Tunis.Diabetes Metab, 2010; 36(3):204-8.

[23] Nguyen T HHD, Tang H K, Kelly P, van der Ploeg H P, Dibley J. Association between physical activity and metabolic syndrome: a cross sectional survey in adolescents in Ho Chi Minh City, Vietnam. BMC Public Health, 2010; 10:141.

[24] Lambert M, Paradis G, O'Loughlin J, Delvin EE, Hanley JA, Levy E. Insulin resistance syndrome in a representative sample of children and adolescents from Quebec, Canada. Int J Obes Relat Metab Disord, 2004; 28(7):833-41

[25] Kelishadi R, Ardalan G, Gheiratmand R, Adeli K, Delavari A, Majdzadeh R. Pediatric metabolic syndrome and associated anthropometric indices: CASPIAN study. Acta Paediatr, 2006; 95(12):1625-34.
[26] Cook S, Weitzman M, Auinger P, Nguyen M, Dietz WH. Prevalence of a metabolic syndrome phenotype in adolescents: Findings from the third National Health and Nutrition Examination Survey, 1988-1994. Arch Pediatr Adolesc Med, 2003; 157(8):821-7.

[27] Park MJ, Boston BA, Oh M, Jee SH Prevalence and Trends of Metabolic Syndrome Among Korean Adolescents: From the Korean NHANES Survey, 1998-2005. J Pediatr, 2009, 155(4): 529-34.

[28] Saito I, Mori M, Shibata H, Hirose H, Tsujioka M, Kawabe H: Prevalence of metabolic syndrome in young men in Japan. J Atheroscler Thromb, 2007, 14(1): 27-30.

[29] Singh R, Bhansali A, Sialy R, Aggarwal A. Prevalence of metabolic syndrome in adolescents from a north Indian population. Diabet Med, 2007; 24(2): 195-9.

[30] Li Y, Yang X, Zhai F, Kok FJ, Zhao W, Piao J, Zhang J, Cui Z, Ma G: Prevalence of the metabolic syndrome in Chinese adolescents. Br J Nutr, 2008, 99(3):565-570.

[31] Friedemann C, Heneghan C, Mahtani K, Thompson M Perera R, Ward $A M$. Cardiovascular disease risk in healthy children and its association with body mass index: systematic review and metaanalysis. BMJ, 2012; 345:e4759.

[32] Schwandt P, Kelishadi R, Haas GM. First reference curves of waist circumference for German children in comparison to international values: the PEP Family Heart Study. World J Pediatr, 2008, 4 (4): 259-66.

[33] Freedman DS and Rimm AA. The relation of body fat distribution, as assessed by six girth measurements, to Diabetes Mellitus in women. Am J Public Health, 1989;79(6):715-20.

[34] Vallianou NG, Evangelopoulos AA, Bountziouka V, Vogiatzakis ED, Bonou MS, Barbetseas J, Avgerinos PC, Panagiotakos DB..Neck circumference is correlated with triglycerides and inversely related with HDL cholesterol beyond BMI and waist circumference. Diabetes Metab Res Rev, 2013, 29(1):90-7.

[35] Dalleck LC, Kjelland EM. The prevalence of metabolic syndrome and metabolic syndrome risk factors in college-aged students. Am J Health Promot, 2012; 27(1): 37-42.

[36] Druet C, Dabbas M, Baltakse V, Payen C, Jouret B, Baud C, Chevenne D, Ricour C, Tauber M, Polak M, Alberti C, LevyMarchal C Druet C, Dabbas M, Baltaske V. Insuline resistance and the metabolic syndrome in obese French children. Clin Endocrinol (Oxf), 2006;64 (6):672-8.

[37] Mo-Suwan L, Lebel L. Risk factors for cardiovascular disease in obese and normal school children: association of insulin with other cardiovascular risk factors. Biomed Environ Sci, 1996; 9 (2-3): 269-75.

[38] Khuwaja AK, Fatmi Z, Soomro WB, Khuwaja NK.Risk factors for cardiovascular disease in school children. J Pakistan Med Assoc, 2006; 53(9):346-50.

[39] Misra A, Khurana L. Obesity and the metabolic syndrome in developing countries. J Clin Endocrinol Metab, 2008; 93 (11 Suppl 1):S9-30. 